isoproterenol

\title{
The Role of Catecholamines in Lung Liquid Absorption at Birth
}

\author{
D. V. WALTERS* AND R. E. OLVER \\ Department of Paediatrics, University College Hospital Medical School, The Rayne Institute, London, England
}

\section{Summary}

We have examined the effect on lung liquid secretion of catecholamines infused in chronically catheterized fetal lambs in utero. Isoproterenol and epinephrine inhibited secretion, an effect which increased with gestation and, in fetuses near delivery, caused absorption of lung liquid. In 7 out of 8 experiments nor-epinephrine had no effect on secretion. This pattern of response and the fact that the inhibitory effect could

* To whom requests for reprints should be addressed at: Department of Paediatrics, University College Hospital Medical School, The Rayne Institute, 5 University Street, London, WCIE 6JF England. be blocked by propranolol indicate a mode of action involving $\beta$-adrenergic receptors.

\section{Speculation}

The observed effects on lung liquid secretion were achieved with infusion rates of epinephrine which are well within the range for endogenous production by the adrenals in response to splanchnic nerve stimulation or asphyxia. Thus the marked increase in the secretion of epinephrine which occurs during parturition may be an important factor in initiating lung liquid absorption. Permanent inhibition of lung liquid secretion postnatally may be due to greater sensitivity of the pulmonary epithelium to $\beta$-adrenergic stimulation and to the higher "resting" output of epinephrine from the adrenals of neonates compared with fetuses. 


\section{Introduction}

The lungs of the fetus are filled with a specialised secretion elaborated by the respiratory epithelium - a process which involves active ion transport (15). In the mature fetal lamb, lung liquid is formed at a rate of some $2-3 \mathrm{ml} / \mathrm{hr} . \mathrm{Kg}$ body weight and occuples a volume roughly equivalent to the Functional Residual Capacity of the newborn: $30 \mathrm{ml} / \mathrm{kg}$ body welght (14). In the course of adaptation to air breathing, the liquid within the lung must be cleared to make way for alr. Although it is wel 1 established that this process takes some 4-6 hours for completion $(2,11)$, how it 18 achieved 18 far from clear. Olver and Strang (15) showed that when active transport in the lung is inhibited by cyanide, absorption of lung liquid takes place down the protein osmotic gradient which exists between this fluld and plasma (- about $20 \mathrm{mmHg}$ ). However, the physiological mechanism for "switching off" lung liquid secretion at birth is not known. Certainly the secretory mechanism must be modifled at this time, so that liquid does not subsequently accumulate in the lungs under normal conditions.

The amounts of catecholamines released in response to splanchnic nerve stimulation and asphyxia increase during gestation in the lamb $(5,7)$ and there is good circumstantial evidence for enhanced catecholamine secretion during parturition (6, 12). denervated) adrenals is greater in the newborn than in the fetus. For these reasons we chose to examine the effect on lung liquid secretion of certain catecholamines in chronic fetal lamb preparations in utero.

\section{Methods}

We performed experiments on lamb fetuses in nine chronically catheterized preparations. The animals used were Dorset Short Horn or Clun Forest ewes whose tupping dates were known.

\section{Surg1cal Procedures:}

Pregnant ewes between 115 and 125 days' gestation were anesthetized with intravenous pentobarbitone sodium ("Sagatal", May and Baker) 300-600 mg, and anesthesia maintained with repeated small Baker) 300-600 mg, and anesthesia maintained with repeated
doses. Under sterile conditions the uterus was approached through a midline abdominal incision. A three to four inch cut was made in the uterus near a fetal head, care being taken to minimise amiotic fluld loss. Two large bore catheters were tied into each end of the incised fetal trachea, and smaller catheters were inserted into a carotid artery and a jugular vein. The uterus and abdomen were closed in layers and the catheters brought out through the uterine incision and then through a flank inout through the uterine incision and then through a flank in-
cision some distance from the abdominal wound. A 5-day postoperative course of penficlilin and streptomycin was routinely given to ewe and fetus.

\section{Catheters:}

All catheters were made of Silastic (Dow-Coming). The tracheal catheters had an Internal diameter $0.264 \mathrm{~cm}$ and were cut to 100 $\mathrm{cm}$ length, giving a volume of $5.5 \mathrm{ml}$ each. Between periods of experimental observations, the two catheters were joined to form a loop so that lung liquid could flow normally through the larynx. The pressure drop along the whole length of the tracheal loop was $1.0 \mathrm{~mm}$ of water at flow rates of $15 \mathrm{ml} /$ hour (usual lung liquid secretion rates in our experiments were between 10 and 15 $\mathrm{ml} /$ hour). Blood catheters had an internal diameter of $0.102 \mathrm{~cm}$ and were cut to $150 \mathrm{~cm}$ length. Catheter volumes were $1.2 \mathrm{ml}$ each and when not being used were filled with a heparin solution (500 units/ml).

The join in the tracheal loop and the junctions of the blood catheters with syringes were wrapped in spirit swabs and kept in sterile polythene bags on the back of the ewe.

The positions of the catheters after death were ascertalned in 8 of the 9 lambs. The tips of the lung tracheal catheters usually produced a slight roughening of the tracheal epithelium but no other signs of damage were seen. The tips of the venous catheters lay between the lower end of the external fugular vein and the superfor vena cava. The tips of the arterial catheters lay between the carotid artery and the arch of the aorta.

\section{Experimenta1 Procedure:}

The first experiment on each fetus was performed not earlier than 6 days after the operation. Subsequent experiments were no more frequent than on alternate days.

The tracheal loop was broken at the join and a syringe attached to the catheter connected to the fetal lung. Lung liquid secretion rate was measured by the impermeant tracer technique (14). A known amount of radio-lodine ( $125_{I}$ or $\left.131_{I}\right)$ labelled albumen was introduced into the lung 1Iquid, which was then thoroughly mixed over a perlod of 30 minutes by repeated withdrawa 1 and reinjection via the tracheal cannula. The total lung liquid volume at any time could be calculated from the tracer concentration and to determine this, lung liquid samples were taken every 5 or 10 minutes (a correction was applied for the small amount of tracer removed with each sample). We adjusted sample volume so that the volume remaining in the lung was approximately constant. After a control period of one hour, one of three catecholamines was infused via the venous catheter, usually for 70 minutes. The ranges of infusion rates used were: isoproterenol $0.15-1.0 \mathrm{\mu g}$ base/min, epinephrine $0.16-3.0 \mu \mathrm{g}$ base/min and norepinephrine $0.18-3.0 \mu \mathrm{g} / \mathrm{base}$ min. In spite of prior filling of the catheter dead space with catecholamine solution, there was often a delay of about 10 minutes before there was any effect on lung ifquid secretion. Therefore, secretion rates were calculated from 15 minutes after the start of the infusion. A 30-minute period of recovery was allowed after the end of the infusion and sampling was then continued for a further hour as a second control period. This sequence could be repeated with variations such as

a different dose, or a different agonist or using an antagonist.

\section{Monitoring of Blood Gases, Blood Pressure and Heart Rate:}

Frequent measurements of $\mathrm{pH}, \mathrm{PaCO}_{2}$ and $\mathrm{PaO}_{2}$ were made. During the control periods the mean value of $\mathrm{pH}$ was 7.423 (S.E.M. \pm $0.013)$ of $\mathrm{PaCO}_{2}$ was $44.4( \pm 1.2) \mathrm{mmHg}$ and for $\mathrm{PaO}_{2} 25.8( \pm 1.0)$ ming. Infusion of the catecholamines did not produce a significant change in any of these values.

Fetal arterial blood pressure and heart rate were continuously monitored via the arterial catheter. The mean control heart rate was $160( \pm 6.4)$ beats $/ \mathrm{min}$. Isoproterenol produced a mean increase of $103( \pm 5.7)$ beats/min. ( $P<0.001)$ but had no significant effect on mean blood pressure. Epinephrine infusion caused an increase of $24( \pm 3.6)$ beats/min in heart rate $(P<0.01)$ but had no effect on mean blood pressure. Norepinephrine infusion had no signiffcant effect on heart rate, but produced an average increase of $6( \pm 2.0) \mathrm{mmHg}$ in mean blood pressure $(p<0.05)$.

\section{Drugs and Chemicals:}

Radiolabelled Albumen, The Radiochemical Centre Ltd., Amersham, Bucks, U.K.

Propranolol hydrochloride, "Indera1", I.C.I., Gt. Britain. Norepinephrine 1:000, "Levophed", Winthrop, England. Epinephrine 1:1000, Antigen Ltd., Ireland.

Is oproterenol hydrochloride 1:5000, "Isupre1", Winthrop, England.

Solutions of catecholamines were made up immediately before each infusion in physlological saline, in such a strength that the volume infusion rate was always the same, viz. $8.8 \mathrm{ml} / \mathrm{hour}$.

\section{Analysis of Samples:}

Welghed allquots (about $0.4 \mathrm{~g}$ ) of the lung liquid samples were counted on a Packard Autogamma scintillation spectrometer with energy gates set between $10-80 \mathrm{KeV}$ for $125 \mathrm{I}$ and $100-450 \mathrm{KeV}$ for

Acute Experiment:

On one of the ewes carrying twins we performed an acute experiment at 136 days' gestation, 20 days after the operation to set up the chronic preparation. The ewe was anesthetized with intravenous pentobarbitone and the twin which had not been prevlously operated on was delivered onto a warmed table, the

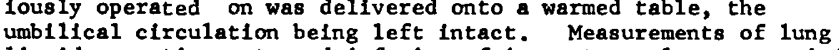
11quid secretion rate and infusion of 1 soproterenol were carried out as described for the chronic preparations.

\section{Spontaneous Labour:}

In the four sheep in which the effects of maturation on the response to infused 1soproterenol were examined, pregnancy was allowed to proceed until the onset of spontaneous labour. This occurred at a mean gestational age of 135 days (range 132-137 days), whereas term in the sheep is usually considered to be 147 days. We attributed this shortening of gestation to the effects of surgery. The mean weight of the lamb fetuses at death was $3.53( \pm 0.29) \mathrm{kg}$.

\section{Results}

\section{Bete-adrenergic effect:}

Isoproterenol and eplnephrine inhibited lung liquid secretion rate or caused absorption of lung liquid in 33 of 36 experiments. Nor-eplnephrine had no effect in 7 out of 8 experiments. A Nor-eplnephrine had no effect in 7 out of 8 exper
summary of all these results is given in Table I.

An example of the effects of the 3 catecholamines is given in Figure 1. Each point represents a volume for accumulated lung liquid (including that removed in samples) at time $t$ calculated from the measured concentration of labelled albumen $\left(C_{t}\right)$. At time $t$,

$$
v_{t}=\left[(X-R) / C_{t} l+v_{s}\right.
$$

Where $V_{t}$ is accumulated 11quid volume, $X$ is the amount of impermeant tracer Initially added, $R$ is the sum of the amounts of tracer removed in previous samples and $V_{s}$ the sum of the volumes of all the previous samples. Calculated regression lines are shown; the slopes give the rate of secretion or absorption of lung inquid.

In this example, 5 minute samples were taken and the first slope gives the control secretion rate; its numerical value is shown just above the horizontal axis. Epinephrine was then infused; this caused lung liquid absorption as indicated by the negative 
slope of the second regression line. After a thirty minute re covery perfod, the slope became positive again indicating that lung liquid was being secreted. Although the secretion rate had not returned to its inftial value, infusion of nor-epinephrine had no effect; the slopes of the $3 \mathrm{rd}, 4 \mathrm{th}$ and 5 th regression ines (before, during and after nor-epinephrine) were not significantly different $(P>0.30)$. However, during isoproterenol infusion absorption took place so rapidy that, after 30 minutes, insufficient 1iquid was present for further samples to be taken. It should be appreciated that although Figure 1 shows progressively increasing accumulated lung liquid volume, the volume inside the lung remained more or less constant at the beginning of each experimental period due to removal of samples). After 90 minutes, liquid had reaccumulated sufficlently in the lung to allow further sampling, and the secretion rate had returned to its initial value. The slopes of the first and last regression lines do not differ $(P>0.40)$. Most of the experiments comprised only one or two infusions of catecholamines.

The beta-adrenergic mode of stimulation suggested by these results was confirmed by the finding that the effects of 1soproterenol and epinephrine could be blocked by propranolol (range 2.0 - $4.8 \mathrm{mg}$ total, $\mathrm{n}-5$ ). The appropriate rate of propranolol infusion was determined emplrically. In all cases the amount given was sufficient to block the cardiovascular response to the infused catecholamine but in two experiments it falled to block the inhibitory effect on lung liquid secretion. These observations suggest that the affinity of the cardiac receptors for propranolol may be appreciably greater than those of the lung epithelium; a point of some relevance to the clinfcal situation epithelium; a point of some relevance to the clinical situat blocked following administration of propranolol to the mother. An example demonstrating blocking of the effect of 1soproterenol on lung liquid secretion 18 shown in Figure 2. Other experiments showed that propranolol given alone had no effect on lung iiquid secretion.

\section{Maturation effect:}

The effect of infused isoproterenol on lung 11quid secretion increased with gestational age. In four sheep the dose of $180-$ proterenol given early in gestation was repeated at least once at a later date. Figure 3 shows the results from aingle fetus into which the same dose of 1soproterenol was infused 4 times between 122 and 133 days ${ }^{\circ}$ gestation. The response increased each time, absorption first occurring at 129 days' gestation and an even more rapid absorption at 133 days' gestation. Results from the four sheep are summarlsed in Table II. In this table it can be seen that the response to isoproterenol infusion ( $\triangle \mathrm{J}_{\mathrm{Y}}$ ) always increased with advancing gestation. This increase in $\triangle \mathrm{J}_{\mathrm{v}}$ is not linear and accelerates towards term, i.e. there appears to be an exponential relationship between $\triangle J_{v}$ and gestation. The slopes of the log-linear regression lines for $\triangle J_{y}$ on gestation for the first three sheep are not significantly different from each other; therefore, we have pooled the data from these animals and added the two points from the fourth sheep. These results are shown graphically in Figure 4, which demonstrates a significant increase in $\Delta J_{v}$ with increasing gestation ( $P<0.001)$.

\section{Acute experiment:}

In the acute experiment performed at 136 days' gestation on fetus which had not previausly been operated on, but which was a twin of a fetus used for chronic experimentacion, the infusion of $0.76 \mu \mathrm{g}$ base/min of 180 proterenol resulted in lung liquid absorption at $27 \mathrm{ml} / \mathrm{hour}$ after a control period during which the secretion rate was $9.9 \mathrm{ml} /$ hour. This result renders unlikely the proposition that previous surgery or repeated doses of catecholamines were responsible for the results described above.

\section{Dlscussion}

These results show clearly that infused catecholamines inhibit the secretion of lung liquid and, particularly in the mature fetus, inftiate its absorption. In achieving this effect both 1soproterenol and epinephrine are much more potent than norepinephrine when comparison is made on an equimolar basis (Table I, Figure 1). This finding suggests that the effect on lung liquid secretion is mediated via beta-adrenergic receptors, an hypothesis borne out by the observation that inhibition of secretion can be blocked by propranolol (Figure 2). As shown in Table II and Figure 3, the sensitivity of the system increases with gestation and 18 maximal at term, at which time we have observed absorption, in response to infused beta-agonists, at rates of up to $40 \mathrm{mi} / \mathrm{hr}$. This absorption of lung liquid has been achleved with epinephrine infusion rates which are well within the range for endogenous epinephrine secretion from the adrenals in response to splanchnic nerve stimulation or asphyxia in fetal lambs, and are of the same order of magnitude as the "resting" adrenal secretion rates of the newborn lamb $(5,7)$. Furthermore, we have observed absorption of lung liquid in the mature fetus in response to the infusion of epinephrine at rates appreclably less than that found to give plasma concentrations of epinephrine $(1.0-3.6 \mathrm{ng} / \mathrm{ml}$ ) comparable to levels following moderate hypoxia (12). Simflar concentrations (mean: $2 \mathrm{ng} / \mathrm{mI}$ ) have been measured In human umbilicsl artery blood after uneventful vaginal delivery, while asphyxia during delivery has been found to give much higher levels (13). Thus, it is quite possible that epinephrine has a causal role in lung liquid absorption at birth, and that this process may begin with the onset of labour. On the one occasion on which we have made measurements during early labour, lung liquid was found to be undergoing spontaneous absorption at $6.0 \mathrm{~m} 1 \mathrm{~s} / \mathrm{hr}$.

With the onset of ventilation, certain changes take place in the lung which can be expected to speed the clearance of liquid. Hydraulic conductivity of the epithelium increases as a result of the "pore stretching" phenomenon described by Egan et al (9), at a time when an hydrostatic gradient is established between afrway and interstitium. Simultaneously pulmonary vasculat resistance falls with a concomitant increase in lung blood flow. We have no information as to whether pulmonary blood flow changes during periods of catecholamine infusion in our experiments, but we believe that such changes cannot account for our findings - for while isoproterenol and epinephrine both inhibit lung liquid secretion, their reported effects on pulmonary vascular resistance in the lamb fetus are opposite $(4,8)$. Furthermore, 0lver and Strang (15) have shown that alte rations in pulmonary haemodynamics, sufficient to cause marked changes in pulmonary lymph flow, have no effect on the rate of lung liquid secretion. We therefore conclude that beta-adrenergic agonists have a specific and direct effect on the mechanism of lung liquid secretion at the level of the respiratory epithelium. Since the process of lung liquid formation involves active ion transport, the flow of solute and water being linked osmotically, inhibition of active solute movement would be expected to halt secretion. In the absence of any active mechanism, water will flow in response to whatever pressure gradients are present. In the fetal lung, plasma and interstitial protein osmotic pressure are some $20 \mathrm{mmH}$ plasma and interstitial protein osmotic pressure are $80 m e$ ming
higher than in lung liquid (3), and thus the direction of passive net volume flow will be from the potential alr spaces into the circulation. Such a reversal of flow has been observed after polsoning of the chloride ion pump of the fetal respiratory epithellum with cyanide (15). However, we cannot exclude the possibility that the stimulation of adrenergic receptors may reverse the direction of net active fon transport and hence water flow. Such a phenomenon occurs in the small intestine in response to a variety of agents (10).

\section{References and Acknowledgements}

1. Adamson, T.M., Boyd, R.D.H., Platt, H.S, and Strang, L.B. Composition of alveolar liquid in the foetal lamb. J. Physiol. 204: 159 (1969).

2. Aherne, W. and Dawkins, M.J.R. The removal of fluid from the pulmonary airways after birth in the rabbit and the effect on this of prematurity and prenatal hypoxia. Biologia Neonat., ?: 214 (1964).

3. Boston, R.W., Humphreys, P.W., Normand, I.C.S., Reynolds, E.O.R. and Strang, L.B. Formation of liquid in the lungs of the foetal lamb. Blologia Neonat., 12: 306 (1968).

4. Cassin, S., Dawes, G.S. and Ross, B.B. Pulmonary blood flow and vascular resistance in immature foetal lambs. J. Phys1o1. 171: 80 (1964).

5. Comline R.S. and Silver, M. The release of adrenaline and noradrenaline from the adrenal glands of the foetal sheep.

J. Physiol., 156: 424 (1961).

6. Comline, R.S. and Silver, M. Composition of foetal and maternal blood during parturition in the ewe. J. Physiol., 222: 233 (1972).

7. Comline, R.S., Silver, I.A. and Silver, M. Factors responsible for the stimulation of the adrenal medulla during asphyxie in the foetal lamb. J. Physiol., 178: 211 (1965).

8. Dawes, G.S, and Mott, J.C. The vascular tone of the foetal lung. J. Physiol., 164: 465 (1962).

9. Egan, E.A., Olver, R.E. and Strang, L.B. Changes in the nonelectrolyte permeability of alveoli and the absorption of lung liquid at the start of breathing in the lamb. J. Physiol., 244: 161 (1975).

10. Field, M. Progress in gastroenterology. Gastroenterology, 66: 1063 (1974).

11. Humphreys, P.W., Normand, I.C.S., Reynolds, E.O.R. and Strang, L.B. Pulmonary lymph flow and the uptake of liquid from the lungs of the lamb at the start of breathing. J. Physiol., 193: 1 (1967).

12. Jones, C.T. and Robinson, R.O. Plasma catecholamines in foetal and adult sheep. J. Physiol., 248: 15 (1975).

13. Lagercrantz, $H$. and Bistoletti, P. Catecholamine release in the newborn infant at birth. Pediat. Res. 11: 889 (1977).

14. Normand, I.C.S., Olver, R.E., Reynolds, E.O.R. and Strang, 14. Permeability of lung capillaries and alveoli to non-electrolytes in the foetal lamb. J. Physiol., 219: 303 (1971).

15. Olver, R.E. and strang, L.B. Ion fluxes across the pulmonary epithelium and the secretion of lung liquid in the foetal lamb. J. Physiol., 471: 327 (1974). 
16. We are indebted to Professor L. B. Strang for his encouragement and advice. Our thanks are due to $\mathrm{Mr}$. C. M. Bright, Miss C. Parcell and Miss E. Evans for technical assistance, and we are grateful to Miss $S$. White for guidance with statistics.

17. D.V.W. was supported by the Birth Defects Trust, U.C.H. Medical School, London and R.E.O. was supported, in part, by The Wellcome Trust under the University Awards Scheme.

18. Received for publication October 12, 1977

19. Accepted for publication January 4, 1978.

Table I. Effect of catecholamines on foetal ling l1 quid secretion.

\begin{tabular}{|c|c|c|c|c|c|c|}
\hline DRUG & $\begin{array}{c}\text { DOSE } \\
\text { Mean \& Range } \\
(\mu \mathrm{g} \text { base/min) }\end{array}$ & $\begin{array}{l}\text { NO. OF } \\
\text { EXPERI- } \\
\text { MENTS }\end{array}$ & $\begin{array}{l}\text { GESTATION } \\
\text { Range } \\
\text { (Days) }\end{array}$ & $\begin{array}{l}\text { EFFECT ON LU } \\
\text { (No. of } \\
\text { Absorptiont }\end{array}$ & $\begin{array}{l}\text { UNG LIQUID SEC } \\
\text { Experiments) } \\
\text { Inhibitiont+ }\end{array}$ & None \\
\hline Isoproterenol & $\begin{array}{c}0.69 \\
0.15-1.0\end{array}$ & $\left(\begin{array}{l}21 \\
\text { ( } 8 \text { sheep) }\end{array}\right.$ & $121-136$ & 8 & 11 & 2* \\
\hline Eplnephrine & $\begin{array}{c}0.60 \\
0.16-3.0\end{array}$ & $\left(7 \begin{array}{l}15 \\
\text { sheep })\end{array}\right.$ & $118-133$ & 2 & 12 & $1 \star \star \star *$ \\
\hline $\begin{array}{c}\text { Nor-Epine- } \\
\text { phrine }\end{array}$ & $\begin{array}{c}0.85 \\
0.18-3.0\end{array}$ & $\begin{array}{c}8 \\
\text { (5 sheep) }\end{array}$ & $120-133$ & 0 & 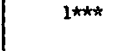 & 7 \\
\hline
\end{tabular}

Mean doses are In molar ratio of Isopr 1.0: Ep1 1.0: Nor-Epi 1.5.

+ Absorption - inhibition of secretion with reversal of direction of flow.

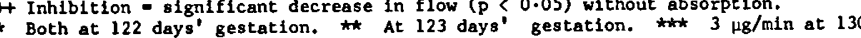
days.

\section{Table II. Effect of maturation on response to isoproterenol.}

\begin{tabular}{|c|c|c|c|c|c|}
\hline $\begin{array}{l}\text { SHEEP } \\
\text { NO. }\end{array}$ & $\begin{array}{l}\text { ONSET OF } \\
\text { LABOUR * } \\
\text { (Days) }\end{array}$ & $\begin{array}{l}\text { GESTATION } \\
\text { (Days) }\end{array}$ & $\begin{array}{l}\text { LUNG LIC } \\
\text { RATE, } \\
\text { Control }\end{array}$ & $\begin{array}{l}\text { UID SECRETION } \\
\text { J }(\mathrm{ml} / \mathrm{hr}) \\
\text { I soproterenol }\end{array}$ & $\begin{array}{l}\Delta \mathrm{J}_{\mathrm{v}} \\
(\mathrm{ml} / \mathrm{hr})\end{array}$ \\
\hline 1303 & 137 & $\begin{array}{l}124^{\circ} \\
127^{\circ} \\
131 \\
134\end{array}$ & $\begin{array}{r}10 \cdot 1 \\
11 \cdot 2 \\
12 \cdot 8 \\
6 \cdot 9\end{array}$ & $\begin{array}{r}7 \cdot 7 \\
2 \cdot 8 \\
4 \cdot 3 \\
-18 \cdot 8\end{array}$ & $\begin{array}{r}6 \cdot 4 \\
8 \cdot 4 \\
8 \cdot 5 \\
25 \cdot 7\end{array}$ \\
\hline 1309 & 136 & $\begin{array}{l}122 \\
126 \\
129 \\
133\end{array}$ & $\begin{array}{r}13 \cdot 2 \\
19 \cdot 1 \\
8 \cdot 9 \\
10 \cdot 5\end{array}$ & $\begin{array}{r}11 \cdot 1 \\
4 \cdot 5 \\
-\quad 9 \cdot 0 \\
-41 \cdot 5\end{array}$ & $\begin{array}{l}2 \cdot 1 \\
14 \cdot 6 \\
17 \cdot 9 \\
52 \cdot 0\end{array}$ \\
\hline $\begin{array}{r}1313 \\
\ldots\end{array}$ & 133 & $\begin{array}{l}126 \\
129 \\
131 \\
133\end{array}$ & $\begin{array}{l}13 \cdot 5 \\
16 \cdot 2 \\
13 \cdot 1 \\
13 \cdot 0\end{array}$ & $\begin{array}{r}6 \cdot 5 \\
7.2 \\
0.3 \\
-11 \cdot 9\end{array}$ & $\begin{array}{r}7 \cdot 0 \\
9 \cdot 0 \\
12 \cdot 8 \\
24 \cdot 9\end{array}$ \\
\hline 1314 & 132 & $\begin{array}{l}127 \\
130\end{array}$ & $\begin{array}{l}11 \cdot 3 \\
15 \cdot 3\end{array}$ & $\begin{array}{r}-1.8 \\
-14.9\end{array}$ & $\begin{array}{l}13.1 \\
30.2\end{array}$ \\
\hline
\end{tabular}

Minus sign denotes absorption.

* Gestational age at onset of labour.

$\triangle \mathrm{J}_{\mathrm{v}}$ is control secretion rate minus secretion rate during isoproterenol infusion.
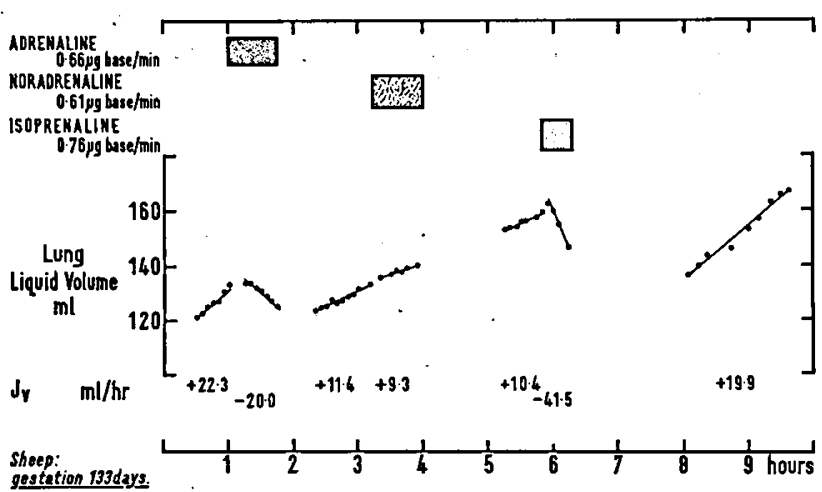

Figure 1. Effect of intravenous catecholamines on fetal lung liquid secretion. Values of accumulated lung liquid volume were calculated as described in the text. The change in lung liquid volume with time ( $\mathrm{J}_{\mathrm{V}}$ ) in any period was obtained from the regression line fitted to the points. Positive values for $\mathrm{J}_{\mathrm{v}}$ indicate secretion, negative values absorption. Epinephrine (Adrenaline), Nor-epinephrine (Nor-adrenaline) and Isoproterenol (Isoprenaline) were infused at equimolar rates.

0031-3998/78/1203-0239\$02.00/0

Copyright $(1978$ International Pediatric Research Foundation, Inc.

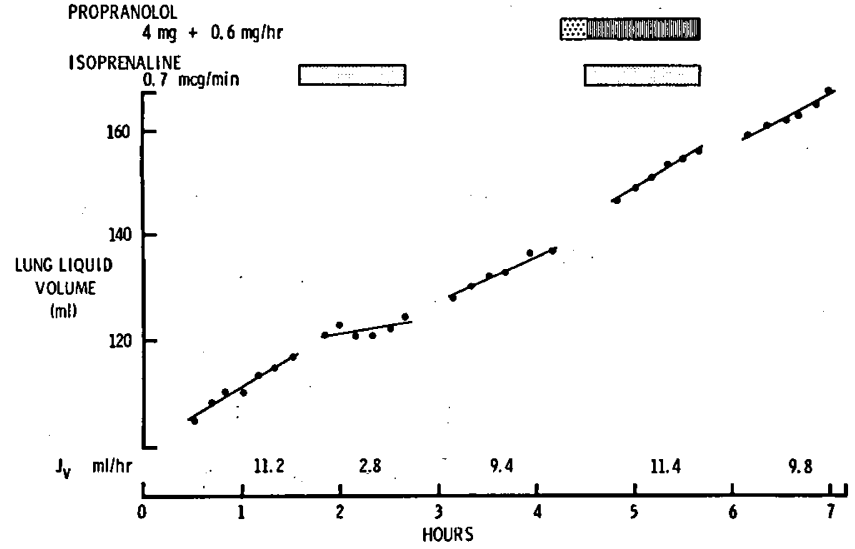

Sheep 1303 Exp. C4 127 days

Figure 2. Blocking of the effect of isoproterenol (Isoprenaline) on fetal lung liquid secretion by propranolol. Both drugs were given intravenously. The infusion of propranolol was preceded by loading dose of $4 \mathrm{mg}$ of propranolol given over 15 minutes.

Isoproterenol alone caused inhibition of secretion; the slope of the second regression line differs significantly from those of the controls on each side $(P<0.01)$. The slope of the fourth regression line (during Isoproterenol + Propranolol infusion) is not different from the controls on each side $(P>0.1)$. The numerical value of each slope gives the secretion rate $\left(J_{v}\right)$ during that period.

Sheep No. 1309

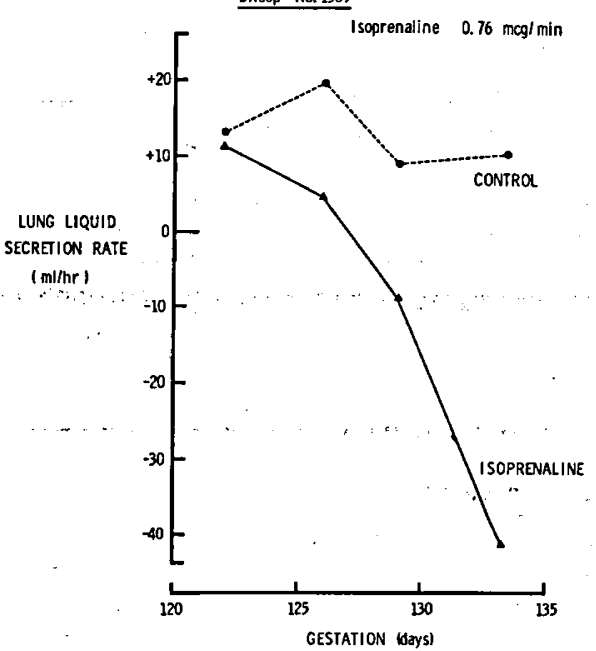

Figure 3. Increasing effect of Isoproterenol (Isoprenaline) on lung liquid secretion with advancing gestational age in a single fetus. The same dose of Isoproterenol $(0.76 \mu \mathrm{g} / \mathrm{min})$ was infused at 4 gestational ages. Negative values for lung liquid secretion rate indicate absorption. = control lung liquid secretion and $\boldsymbol{\Lambda}=$ the secretion (or absorption) rate during Isoproterenol infusion which immediately followed the control period.

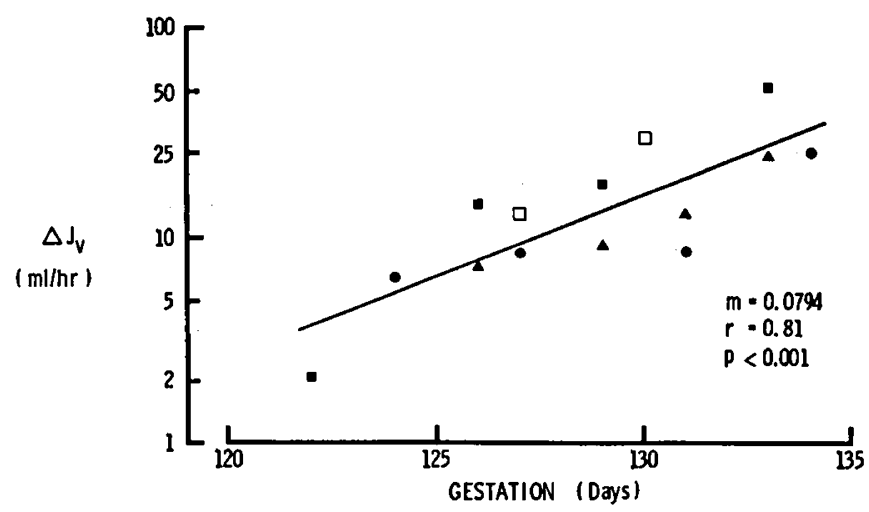

Figure 4. Increasing effect of Isoproterenol (Isoprenaline) on fetal lung liquid secretion with advancing gestational age pooled data from Table 2. $\Delta \mathrm{J}$ plotted logarithmically.

$\left(\Delta \mathrm{J}_{\mathrm{v}}=\right.$ the difference between $\mathrm{v}_{\text {control secretion rate and that }}$ observed during Isoproterenol infusion). values from sheep No. 1303 , from sheep No. 1309, $\Delta$ from sheep No. 1313 and $\square$ from sheep No. 1314 .

Printed in U.S.A. 